\title{
Verzeichnis der (abgekürzten) Kreisnamen
}

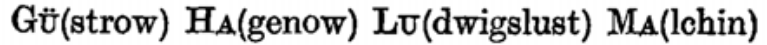 \\ $\mathbf{P}_{\mathrm{A}}$ (rchim) Ro(stock) ScHö(nberg) ScHW(erin)
}

$\mathrm{ST}_{\mathrm{A}}$ (rgard) $\mathrm{W}_{\mathrm{A}}$ (ren) $\mathrm{Wr}$ (smar)

\author{
ISBN 3-05-000404-5 \\ Erschienen im Akademie-Verlag Berlin, DDR - 1086 Berlin, Leipziger Str. 3-4 \\ (C) Akademie-Verlag Berlin 1987 \\ Lizenznummer: $202 \cdot 100 / 104 / 87$ \\ Printed in the German Democratic Republic \\ Gesamtherstellung: IV/2/14 VEB Druckerei oGottfried Wilhelm Leibniz,, \\ 4450 Gräfenhainichen $\cdot 6696$ \\ LSV 0817 \\ Bestellnummer: '754 7417 (3016/56)

